\title{
An Optimization Study on Recruitment System of C Company From the Perspective of HR Three-Pillar
}

\author{
Xiang Li ${ }^{*}$ \\ School of Economics and Management, Beijing Jiaotong University, P.R.China, 100044 \\ ${ }^{*}$ Corresponding author. Email: kitolee@bjtu.edu.cn
}

\begin{abstract}
The HRBP model-based recruitment system promises a professional and targeted recruitment of employees, and the recruitment system would have to be adjusted if business strategies should be changed. This study tries to deal with the difficulty that BU personnel recruitment system of C Co., Ltd. has fell behind HR strategies, which has fully implemented the Three-Pillar model, by positioning analysis of roles \& duties of C's HR Three-Pillar and systematic elaboration of recruitment system based on the pattern of HRBP. It also proposes improvement suggestions for the division of C's Three-Pillar roles and recruitment process.
\end{abstract}

Keywords: HR Three-Pillar, HRBP model, Recruitment system.

\section{INTRODUCTION}

Under the background of knowledge-driven economy, large businesses have set out to seek the reformation of HRM mode, so that the HRD gradually got rid of the transactional role and moved to a strategic one oriented by business. Due to its characteristics of strategic starting and business guidance, the HR ThreePillar model has been led to a growing popularity in the practice of corporate HRM among several theories. C company is a foreign-funded enterprise mainly engaged in providing diesel and electric power solutions, which adopts the diversification strategy and divisional organization. With the expansion of enterprise scale and business scope, the recruitment system of C company inevitably falls behind the enterprise strategies. This study aims to diagnose, update and optimize the recruitment system under the HRBP model in BU for $\mathrm{C}$ company that have already implemented the HR ThreePillar architecture, and based on the current HR strategies of this company.

\section{LITERATURE REVIEW}

While the HRD of an enterprise isn't faced with external customers directly, it always faces internal customers, that is, it serves the employees of the enterprise and needs to coordinate the needs of different employees at the same time. Dave Ulrich put forward the HR Three-Pillar model in 1996, who adhered to the management philosophy of "focusing on customers" and required the HRD to shift from being function-oriented to being business-oriented and operate like a BU to realize business value-added [1]. Ulrich integrated HRM into 3 departments: Center of Expert (HRCOE), Business Partner (HRBP), and Shared Service Center (HRSSC). The three mainly correspond to 3 types of customers with different needs for HR service: strategic decision makers at high-level, business executors at middle-level and ordinary employees at basic-level.

Rao et al. constructed an integrated framework of model research, clarified the topic of "HRM becomes a business partner", and emphasized the core position of HRBP [2]. Martin McCracken et al. drew the conclusion that HRBP model makes HRM more strategic, which supported the viewpoints of Rao, and proposed that regulations ensure an effective HRBP model [3]. Huang proposed that HRBP is facing the challenge of role positioning, who also believed completing HRM internal processes and repositioning the role responsibility of HRBP in BUs is the key to the practice of Three-Pillar in an enterprise [4]. On the role positioning of HRBP, Shi et al. emphasized the integrity of Three-Pillar and believed the 3 pillars ought to perform their functions, respectively strategic, tactical and operational responsibilities [5]. Wu et al. elaborated on this integrity by using the recruitment system, and supposed COE should formulate recruitment policies and procedures, while HRBP grasp recruitment 
standards, and SSC convey employment info to the external environment [6]. Starting from the holistic characteristics of HR Three-Pillar model and using different research methods, studies above virtually require $\mathrm{COE}, \mathrm{HRBP}$ and $\mathrm{SSC}$ to maintain consistent values and service business based on strategies in the application of recruitment system. Furthermore, Dang proposed the unity of enterprise internal values is of significance to the implementation of HRBP model [7]. In addition to the clear division of responsibilities of 3 pillars, of HRM, there're still several supplements for the role transformation to HRBP. Zheng considered strategic starting and business guidance as the essence of HRBP model. He also believed attention should be paid to HRBP thinking in the optimization process of HRM [8]. Li constructed a theoretical research system of HRM role development and put forward the boundary-crossing role of HRM is to redefine the value of enterprise HRM and considered HRM as a connection builder that participates in external cooperation actively [9]. The studies above respectively provide tools for the optimization of enterprise HRBP model, namely HRBP thinking and the role of connection builder.

Yu found 3 main problems in recruitment through questionnaire survey, namely conflicts between recruitment system and reality, unreasonable recruitment process and unclear selection criteria. But he didn't provide with a clear answer to clarifying screening criteria [10]. Besides, Liu believed screening criteria should be formulated according to the needs of business departments, and proposed the recruitment characteristics of introducing basic specialization, coordinating the introduction process and precision of the introduction results under HRBP model [11]. Wu and Lu improved the design of the recruitment system of basic-level and middle-level staff respectively. The former believed the recruitment of basic-level staff is of vital significance to the recruitment system of large manufacturing enterprises [12], while the latter believed the one of middle-level staff involved the process of talent introduction, which is related to the mutual adaptation of talent layout and strategic objectives [13].Shao and Qian both pointed out the optimization and adjustment of recruitment system are supposed to support business development from a strategic perspective by developing and applying multi-level recruitment tools and introducing practical standardized procedures [14]. In view of middle-level staff recruitment for large manufacturing enterprises, Qian also proposed that the basic-level staff recruitment is the foundation, the management of which can be standardized through a well-designed process system, and the middle-level staff recruitment is the key which requires a good combination of process system, personalized talent project, enterprise strategies and business operations [15]. Du et al. shed a different light and proposed the "HRBP model based on service recovery" from the perspective of post-feedback, believing the service recovery system to be capable of providing timely feedback to fill the gaps [16]. In conclusion, existing optimization methods of recruitment system mostly take business strategies of the enterprise as the starting point and urge the HRD to develop screening criteria according to the needs of business departments, with promoting the standardization of recruitment system and processes from levels of the basic and the middle respectively. Moreover, the introduction of service recovery system as an active control means into the staff recruitment system is conducive to the purpose of continuous active optimization of the system.

\section{OVERVIEW OF C'S HRM STRUCTURE}

\subsection{History of HRM Mode Transformation}

C company has a relatively advanced HRM system. The transformation to the HR Three-Pillar of $\mathrm{C}$ company's HRM started early and achieved fruitful results. In 1998, as a starting point of the standardization of HR policies and procedures at the overall level of the enterprise, C company's HQ in America established the HRSSC. In 2005, under the guidance of HQ, C company proposed HR Three-Pillar as the main HR structure for the first time in its corporate strategy and established HRSSC. After this formation, HRD was redivided into 3 groups based on HR Three-Pillar model, which is still in use today.

\subsection{Status of HRM Structure}

HRD in C company has been divided into 3 groups, collectively known as "strategic partners", including Corporate HR (HRCOE), CBS HR (HRSSC) and Line HR (HRBP). The 3 groups make up the structure that $\mathrm{HQ}$, BU and SSC are mutually supporting. HR groups at different levels have diverse functional emphases, independently exist and operate closely in the design, development and implementation of HR strategies, and jointly support the business development of the company.

(1) Corporate HR focuses on "Strategy \& Policy Design", who's mainly responsible for corporate HR strategies and policy formulation and process design optimization and provides professional HR consulting services to the enterprise senior as a think-tank.

(2) CBS HR is part of Global Business Services Dept, providing HR services to 7 business areas around the world. The HR shared service of C company is provided by CBS HR of Northeast Asia Business Service Dept, whose focus is "Service delivery", mainly responsible for providing internal control \& orientation, 
salary plan, health \& welfare, global dispatch and other services to all employees.

(3) Line HR's focus of work is to "maintain accurate employee records". 5 BUs in C company are all equipped with Line HR dept, mainly be responsible for assistance to BU directors in HR planning, policy \& process interpretation, to carry out the management and support BU for staff recruitment and talent training, undertake analysis on BU personnel, staff file management and administrative work. Additionally, demands in BU that can't be met by Line HR will be fed back to Corporate HR and CBS HR for system or service support.

\subsection{Current Problems of HRM System}

C company attaches great significance to HR planning function of $\mathrm{BU}$, endowing Line $\mathrm{HR}$ with considerable strategic value and relatively high workload. With the expansion of enterprise scale and business scope, C company's recruitment system has fallen behind the corporate strategies inevitably. Due to the absence of administrative dept, Line HR, as the only dept related to administration in $\mathrm{BU}$, is required to undertake numerous transactional work such as database management, access control management, etc. In the long run, staff of BU regard transactional work as part of Line HR's responsibilities. At the same time, the heavy workload has intern and basic-level staff recruitment directly handed over to CBS HR, about which supervisors are fed up. They believe that CBS HR's understanding of HR forecast about BU is not as good as Line HR's, and the direct access to recruiters from CBS HR is difficult to gain, giving rise to the unexpected quality of candidate.

\section{PROBLEM DIAGNOSIS}

\subsection{Survey Results of Employee Satisfaction}

In the past 5 years, the turnover of basic-level and middle-level employees in 5 BUs in $\mathrm{C}$ company fluctuated around $21 \%$ and $15 \%$ respectively. In the survey of employee satisfaction, C company has an assessment indicator as NPS (Net Promotor System) index, aiming to track and quantify the satisfaction and loyalty of employees, so as to locate the factors of dissatisfaction to implement optimization measures. NPS index classifies employees into 3 categories by using a satisfaction score. Those with a score of 0-6 are "the derogators", 7-8 are "the passives", and 9 to 10 are "the promoters". NPS index is defined as

$$
\text { NPS index }=(\text { Promoters } \%-\text { Derogators } \%) \times 100 \text {. }
$$

It measures how willing employees are to recommend a service to a business partner or colleague. In the survey above, NPS index was used to analyze the satisfaction on the recruitment system under HRBP model of each interest group in BU.

The managers' cognition of recruitment processes is significantly better than that of the recruitment system and HR Three-Pillar model, while Line HR has a good understanding of these. Senior managers and supervisors of $\mathrm{BU}$ are familiar with the recruitment processes, but most of them have a "general" or "basic" grasp of recruitment system. Different from Senior managers' satisfaction of recruitment system, supervisors graded recruitment process and recruitment flow by NPS index of 70.83 and 75.00, whose level are much lower than other groups. Reasons for this phenomenon are mainly as follows: low efficiency of examination \& approval procedures, incompetent candidates that don't meet recruitment requirements, and incompetent new hires.

Employees of BU spoke highly of the recruitment system, with NPS index of 95.35, showing high degree of satisfaction. The evaluation of recruitment process and implementation was followed by NPS index of 84.30, appearing moderate degree of satisfaction. The lowest evaluation is that of post matching, with NPS index of 15.53, expressing as strong dissatisfaction. Thereinto, most of the senior managers, supervisors and employees in BU deem post matching barely satisfactory, and generally gave a medium rating of 7-8 points.

\subsection{Problems of the Recruitment System}

The employee satisfaction survey of recruitment system in C company covers all Bus, and the respondents are mainly supervisors and employees. The survey results are representative, for the interests of both the supplier and the demander of $\mathrm{HR}$ in BU were taken into account.

The survey results on the actual role of HR ThreePillar indicate that Corporate HR plays a main role of strategy designer \& controller, accounting for $99.42 \%$ of the respondents. CBS HR plays a main role of $\mathrm{HR}$ service provider, accounting for $100.00 \%$. Line HR plays 3 main roles simultaneously: change promoter, business partner, employee listener \& motivator, accounting for $88.95 \%, 98.25 \%$ and $95.93 \%$ respectively, and the secondary role of HR service provider, accounting for $36.05 \%$. In the common cognitive of employees, actual roles of the 3 pillars are basically consistent with corporate HR strategies, namely, the main roles of 3 pillars are Corporate HR strategy designer \& controller, CBS HR - HR service provider, Line HR - business partner, change promoter, employee listener \& motivator. Therefore, they could maintain a high degree of consistency in $\mathrm{C}$ company's recruitment policies. 
Among the managers surveyed, the overall mean value is 8.45 , and the coefficient of variation is 0.1452 . The mean value of supervisors is 8.23 , which is obviously lower than the group average of 8.85 and 8.80 of senior managers and Line HR. The mean score of consistency of recruitment system was 9.05, and the coefficient of variation was 0.0996 . These figures reflect that managers surveyed generally gave high comments on the consistency of recruitment system maintained by HR Three-Pillar, believing that Line HR's interpretation of recruitment policies is correct and the design of recruitment service from CBS HR is practical and effective. Nevertheless, for supervisors, there's a disagreement about the division of responsibilities among Three-Pillar, with a low satisfaction, showing that 3 pillars failed to meet the demand for recruitment, to which in a timely manner Line HR needs to respond and provide institutional or service feedback to Corporate HR or CBS HR as soon as possible.

After the diagnosis, this study believes that there're the following problems in the recruitment system of $\mathrm{C}$ company's business division.

(1) Resulting in a remarkably lower understanding of recruitment strategies by managers outside of HR dept, the implementation of recruitment policy interpretation by Line HR is not in place, which makes it difficult for supervisors to report the deviation between current Corporate HR strategies and actual needs.

(2) In BU's recruitment processes, the inefficient examination and approval procedures, candidates not meeting post requirements led to the dissatisfaction of some supervisors, and the situation that post matching degree of new hires being at a low level is quite common.

(3) In the common perception of employees, Line HR deviates from the original secondary role, namely "HR service provider", which overlaps responsibilities and confuses roles with CBS HR in practice.

\section{OPTIMIZATION DESIGN}

\subsection{Optimization of Responsibility Division}

Based on the existing HR Three-Pillar structure of C company, it is suggested that Corporate HR should formulate policies to put such transactional work such as database management, access control management under the unified management of CBS HR, and to regulate the responsibility division and processes for the recruitment of interns and basic-level staff, which requires Line $\mathrm{HR}$ to be responsible for collaborating with supervisors to meet business needs and conduct a secondary resume screening, and CBS HR to be responsible for recruitment information posting and preliminary resume screening, so as to separate Line HR from HR service provider, a secondary role, and define the boundary between CBS HR and Line HR. In practice, quite a lot of transactional work needs to be done within BU after internal examination and approval or personal delivery, and CBS HR is located in Wuhan while HQ is in Beijing, so the advice is that CBS HR should send 1 or 2 specialists to Line HR, who are responsible for transactional work, and provide face-toface HR shared services support at the same time, leaving CBS HR a better understanding of BU's recruitment to improve the quality of support services. Meanwhile, it is suggested that Line HR introduce the role of relationship builder \& maintainer in addition to the 3 main roles of change promoter, business partner and employee listener \& motivator. A relationship builder engages in cross-border relationship building activities aimed at enhancing bilateral exchanges and trust, and a relationship maintainer plays a role in promoting bilateral commitments, which is a prerequisite for in-depth cooperation between organizations. Due to the job characteristics, Line HR could get personnel career development information more easily through industry associations, headhunters and third-party sources such as industry, relying on formal or informal communication to realize the information flow, achieving the goal of effective control of bilateral relations, maintaining good personal relationship with external stakeholders.

\subsection{Optimization of Recruitment Process}

Based on the existing recruitment process of middlelevel and basic-level staff in C company, Corporate HR is recommended to modify the processes after measuring the time cost and work accuracy. After the employment application is submitted by a supervisor, the staffing review is not required to be conducted by a Line HR director, but by a Line HR manager designated by the director, which reduces the audit items and avoids the blocking of audit processes. This improvement measure reduces the transactional work of Line HR director and could focuses more on HRBP's own role. It also improves the efficiency of the recruitment process and reduces the time interval between supervisors' requests and the new hires' entry significantly.

\subsection{Optimization of HRBP Model}

\subsubsection{Emphasizing on HRBP Thinking}

"No matter which HRBP model an enterprise practices, having HRBP thinking is always the most critical" [8]. In order to cope with the rapidly changing internal and external environment of the enterprise, Line HR should pay attention to the cultivation of HRBP thinking of its own team. Firstly, Line HR could use strategic thinking to participate in the company's 
strategic planning indirectly and provide advice to company management from a business perspective by reporting the front-line HR demands of BU to Corporate HR. Secondly, Line HR could use products thinking to grasp latest business development and product trends of business lines, fully understand the industrial information and business development direction of the enterprise, so as to show more professionalism in the role of change promoter and business partner, and realize professional management of professional talents. Thirdly, Line HR could use customer thinking guided by internal customers, employees of $\mathrm{BU}$, to conduct front-line research within the scope of management, analyze the gains and losses of individuals and organizations from the perspective of employees, and thus determine the standards that should be implemented in the work. Finally, Line HR could use innovative thinking to adhere to management innovation, constantly achieve "maintain accurate employee records" from a new perspective, so as to continuously meet the new needs of supervisors. In terms of recruitment system, through enhancing HR HRBP thinking and blending recruitment policies, hiring processes in Line HR's daily communication links with supervisors, it increases mutual understanding.

\subsubsection{Introducing Service Recovery System}

Due to the changeful business environment and communication defects of HRBP model, HRBP often fails in the process of serving the business department, resulting in the inability to meet $\mathrm{HR}$ needs and "accompanied by dissatisfaction and disappointment of the business department, it also causes losses to the enterprise's human resource reserve"[16]. This situation of C company is reflected in that some supervisors think that candidates in the recruitment process often do not meet the requirements, and most employees are less satisfied with the matching degree of the positions than expected. Line HR needs to quickly identify problems and carry out remedies to minimize the loss caused by HRBP service failure, restore the service to the effective state as soon as possible to meet the needs of BU, reduce the negative evaluation of recruitment system by supervisors, and rebuild the image of Line $\mathrm{HR}$ as a reliable business partner.

Service recovery is a process that focuses on continuous improvement of the problems. It is suggested that Corporate HR introduce service recovery system for service failure and carry out implicit and explicit service recovery together with Line HR, BUs and CBS HR. Implicit remedy refers to the remedy of the loopholes in recruitment system of basic-level employees in BU, such as the failure caused by the ambiguity of the responsibilities of HR Three-Pillar or the neglect of the actual business needs. Training and incentive measures should be adopted for Line HR, and the remedy process is limited within the 3 pillars. Explicit remedy refers to the remedy for the failure of recruitment system caused by external environmental factors. For example, during the implementation of the company's recruitment system and recruitment processes, the change of industry environment and some original parts of the system is no longer applicable, so Line HR needs to cooperate with business departments to solve the problem. Through investigations, interviews and so on, once Line HR find out that BU's recruitment system fails, the service recovery system will come into effect immediately. Line HR needs to report failure problems to Corporate HR promptly and send carbon copies to CBS HR business related. Among the 3 strategic partners of HRD, Corporate HR conduct the analysis of causes of failure and formulate reasonable remedies, with the cooperation of Line HR and CBS HR. Corporate HR will feed back the service recovery plan to Line HR, CBS HR and corresponding business departments, and Line HR implements the service recovery plan mainly. CBS HR provides corresponding shared service support and business departments provide analysis reference for external environmental factors, so as to achieve effective services and the goal of meeting the needs of BU finally.

\section{CONCLUSIONS}

The main conclusions of this study are as follows.

(1) The actual responsibilities and role positioning of HR Three-Pillar in C company are basically consistent with corporate strategies, and C company maintains overall consistency in terms of recruitment system and strategies. However, Line HR in practice, undertake a lot of transactional work due to the defect of ThreePillar model design, and there are overlaps of responsibilities and role confusion with CBS HR in practice.

(2) The design of C company's BU recruitment process is defective, and supervisors consider the recruitment approval process to be complicated and inefficient. "Service failures" occurred in recruitment process, resulting in the low matching degree of new hires and candidates do not meet recruitment needs.

(3) It is suggested to redraw the responsibility and role boundary between Line HR and CBS HR by making up for flaws of HR Three-Pillar model design, introduce the role of relationship builder \& maintainer to Line HR, and seek broader and deeper external cooperation in recruitment as well as other HRBP transactions. It is also suggested to optimize recruitment process in personnel staffing review and strengthen strategy thinking, product thinking, customer thinking and innovative thinking for Line HR. The service recovery system is supposed to be introduced to restore 
the effectiveness of recruitment services and the confidence of BUs.

\section{REFERENCES}

[1] Dave Ulrich, Human Resource Champions, Harvard Business Press, 1996

[2] Rao Ronghao, Duan Chengyao, Knowledge Structure and Development Trend of HRBP Model Research: an Analysis Based on Knowledge Map, Foreign Economics and Management, 2017, 39 (04): 98-116+128(in Chinese)

[3] Martin McCracken, Norma Heaton. From Tucked away to Joined at the Hip: Understanding Evolving Relationships within the HRBP Model in a Regional Energy Company. Human Resource Management Journal, 2012, 22(2): 182-198

[4] Huang Yeqing, Research on Improvement of HRBP Function in Organizational Reform of BW Enterprise, Chengdu: University of Electronic Science and Technology, 2018(in Chinese)

[5] Shi Guangjun, Zhu Zhendong, Journal of China University of Petroleum (social science edition), 2016,32 (05): 13-18(in Chinese)

[6] Wu Xiaojian, Kou Weihao, Optimization of Recruitment System Based on HRBP Management Model: a Case Study of X Company, China Human Resources Development, 2015(20): 11-15(in Chinese)

[7] Dang Suxiang, Study on HRBP Management Model of S Software Company, Beijing: University of International Business and Economics, 2017(in Chinese)
[8] Zheng Chaoyang, Practical Research on Largescale Enterprises' HRBP Model, Beijing: Capital University of Economics and Business, 2018(in Chinese)

[9] Li Juan, Research on the Role Development of Enterprise Human Resource Management, Tianjin: Nankai University, 2014(in Chinese)

[10] Yu Lei, Research on Optimization of H Group's Human Resource Management System, Beijing: Beijing Jiaotong University, 2017(in Chinese)

[11] Liu Yang. Research on the Application of HRBP Model, Beijing: Capital University of Economics and Business, 2016(in Chinese)

[12] Wu Fan, Research on Recruitment System of Basic-level Staff in FSN Enterprise, Changchun: Jilin University, 2017(in Chinese)

[13] Lu Qiming, Research on Optimization of Middlelevel Personnel Recruitment System of X Enterprise Based on HRBP, Nanjing: Southeast University, 2018(in Chinese)

[14] Shao Ziyi, Study on Dilemma and Solution of MP Company's HRBP, Hubei: Huazhong University of Science and Technology, 2015(in Chinese)

[15] Qian Daisi, Research on Staff Recruitment and Retention of Bosch \& Siemens, Nanjing: Nanjing University, 2014(in Chinese)

[16] Du Jing, Mu Huina, Improvement of HRBP System from the Perspective of "Service recovery", China Human Resources Development, 2013(17): 48-51+67(in Chinese) 